\title{
Calibration of Payload Measurement System for Mining Haul Trucks
}

\author{
Muhammad Raza \\ Department of Mining Engineering, University of Engineering \& Technology, Lahore \\ *Corresponding Author: Muhammad Raza, Department of Mining Engineering, University of \\ Engineering \& Technology, Lahore
}

\begin{abstract}
Payload measurement systems on haul trucks are a key aspect in production planning and implementation in surface mining industry and are an important component on large mining haul trucks. This system provides production information and helps with run for reliability. An accurate payload management system results in improved hauling efficiency, equipment and tire life, and haul-road maintenance. The truck manufacturers use a range of methodologies for payload measurement that need calibration over time for accuracy of measurement and to avoid overloading of trucks and other conveying equipment. This paper reviews the different methodologies used for payload measurement and describes a working scheme used to calibrate the payload measurement systems for mining haul trucks. This may be used towards standardization of the on-truck payload measurement systems. A case study is presented where this approach was used for calibration purposes.
\end{abstract}

Keywords: payload measurement; payload calibration; mining; haul truck

\section{INTRODUCTION}

Payload systems on haul trucks are a key aspect in production planning and implementation in surface mining industry and are a useful and important component on large mining haul trucks. This system provides production information and helps with run for reliability. Accurate payload measurement is not only important for the efficient production but is crucial for optimum equipment life expectancy and longevity. While an overloaded truck may cause damage to equipment structural integrity, an under loaded truck results in inefficient truck utilization. The general trend in the mining industry is towards overloading equipment specially the haul trucks. This stems from the "excavate more" philosophy and the growing global material demands. Quite often, the employee appreciation awards are also rewarded for more productive operators. This trend, however, results in severs negative impact on the excavation and hauling equipment. An accurate payload measurement system is critical to keep the percentage of overloads within the recommended limits. Generally, the recommended payloadis that $50 \%$ of loads should be less than the target payload. See also caterpillar 10/10/20 rule(Caterpillar, 2008)

The overloaded trucks impact negatively on safety, environment, equipment maintenance, equipment downtime, road conditions, and production costs. An overloaded truck negatively affects safety as it might exceed the maximum braking and steering limits of truck. Some mines might lose their mining license because of overloaded trucks as reports indicate that the Goa state of India is going to cancel the mining leases operating overloaded trucks (Great-Mining, 2011). A list of safety risks involved with the overloads and the measures and recommendations to combat the overloads can be found at this website(miningsafety.co.za).

Overloaded trucks are a big source for road damage as well. There may be as high as $300 \%$ increase in road damage with $40 \%$ increase in overloads (AFRICA, 2011). The fuel consumption of the haul trucks also increases with the payload. Many researchers report a direct relationship of fuel consumption of haul trucks with the loading. Runge (1998) and Filas (2002)modeled the hourly fuel consumption(FC) as equation 1. 
$\mathrm{FC}=\mathrm{P} * 0.3^{*} \mathrm{LF}$

Where $\mathrm{P}$ is engine power $(\mathrm{kW}), 0.3$ is a unit conversion factor and LF is engine load factor. Similarly, Hays (1990) report a direct and linear relationship of fuel consumption with the load factor. Engine load factor values are defined as below: (Caterpillar, 2009)

- Low: 35\%-50\% (Continuous operation at an average gross weight less than the recommended. Excellent haul roads. No overloading, low load factor)

- Medium: 50-65\% (Continuous operation at an average gross weight approaching the recommended. Minimal overloading. Good haul roads, moderate load factor)

- High: $65 \%$ - 80\% (Continuous operation at or above maximum recommended gross weight. Overloading, poor haul roads, high load factor)

The overloaded trucks impact the environment as well. Kecojevic and Komljenovic (2010) reported a strong correlation between fuel consumption and engine loads and showed that a $10 \%$ decrease in load factor can significantly reduce the fuel consumption, $\mathrm{CO}_{2}$ emissions, thereby consequently reducing operating costs. Soofastaei, Aminossadati, Kizil, Knights, and Technology (2016) reported that significant savings in fuel consumption were possible by decreasing the payload variance. Ontruck payload systems are an important technology to reduce the payload variance.

\section{ON-Truck Payload Systems}

Haul truck loading up to its recommended capacity is important; and is achieved via an accurate ontruck payload measurement system. Modern mine haulage trucks, therefore, come with on-board scales that are capable of measuring or estimating the payload in their trays.

The need for on-board truck payload has long been recognized and, as a result, research has been done in this regard. Previous mining systems used the fixed ground scales for truck payload measurement. These systems work wellto determine the system accuracy, however, these fixed ground scales are not useful for effective load management and decrease the system efficiency by increasing haul distance and cycle time.

Most of the payload measurement systems developed so far used the strut pressure as a pay load indicator. These systems are generally patented because of their commercial significance. Foley, et al. (1987) in his Payload Monitor, US patent number 4635739 issued on January 13, 1987,devised a payload monitor using the pressure sensors in the struts to record the payload in the truck. The Payload Monitor continuously updates the payload until the pressure sensors show a stable value for 5 seconds, after which the load is recorded as the payload. However, this payload is not recorded as the final payload in the truck until the pressure sensors continuously observe changes in pressures for 30 seconds. Moreover, this system might give multiple and varying payload values if the truck stops for few seconds during its journey. Further, the system reliability is dependent upon the strut system and decreases as the system wears out. Sorrells (1989) introduced a method for payload monitoring, US Patent 4835719 issued on May 30, 1989, which used green and red lights as indicators of truck payload and as guides for the excavator operator.

Kyrtsos and Gudat (1993) introduced his Dynamic Payload Monitor, US Patent 5182712 issued on Jan 26, 1993, to overcome the errors of Foley et al. (1987)Payload Monitor due to wear of struts, tires, suspension and frame. The Dynamic Payload Monitor measures the payload using the suspension strut pressure while the vehicle is in motion. The researchers claimed that the suspension pressure gave more accurate reading of the payload when the machine is in motion because the dynamic friction in the struts is lesser (almost negligible) than the static friction. This system, however, requires that the vehicle encounter a bump or hole on the road to calculate the readings. This bump or hole on the haul road may or may not be present.

Kevin, Ronald, and Joes (2003) patented "Method and Apparatus Configured to Determine the Weight of a Machine Payload", US Patent 6601013 B2 issued on July 29, 2003, in which they described the system as an improvement to the Kyrtsos \& Gudat(1993). The system described utilized the strut pressure in one of the struts and the force and torque characteristics as indicative of the dynamic force associated with the machine. The system measures the payload weight from the pressure sensor in one of the struts and the torque sensor threshold. The $2^{\text {nd }}$ gear is established as a torque threshold (i.e. the torque is negligible enough to affect the strut compression). 
Bender (2005) patented "Dump Truck With Payload Weight Measuring System And Method of Using Same", US patent No. 6858809 B2 issued on Feb 22, 2005 filed on Dec 3, 2002, and described a modification to the payload measurement system as described by Kyrtsos and Gudat (1993)for accuracy and used the load pins and strain gauges to estimate the payload. The author claimed that the system was accurate because it was not affected by the strut friction and bending, and accuracies of plus or minus $3 \%$ and in many cases better than plus or minus $1 \%$ error could be measured. Furthermore, the accuracy increased as the strain gauges could be made sensitive in the range close to target payload of the truck.

The on-board truck payload measurement systems have been a continuous topic of research and development and there are various approaches to measure payload. Most of the payload measurement systems measure only when the truck is in motion and there is still a margin of improvement in the accuracy. As the trucks are loaded by shovels, therefore, a shovel payload system could also provide the same measurements.

\section{Shovel Payload Measurement}

To achieve efficient and consistent hauling operation it is important that the shovel operator gets an accurate measure of the payload in the truck while loading. The modern on-board payload measurement systems for trucks only measure accurately when they haul starts. Having an accurate shovel payload measurement system is better in many ways. It is helpful for the shovel operator to load the truck to its capacity avoiding overloads and under loads. Furthermore, given the fact that there are always fewer shovels as compared with the number of trucks, it is easier to maintain and keep the shovel payload systems calibrated as compared with the truck on-board payload measurement systems.

Mcaree and Wauge (2012)gave a description of the past work done for shovel payload estimation and invented a "payload estimation system and method", US Patent application number 20090187527 published on July 23, 2009, in which they proposed a three-step procedure for payload estimation for electric mining shovels. In the $1^{\text {st }}$ step, a series of Kalman filter approximations are created to the weight bearing machinery for different levels of payload; in the $2^{\text {nd }}$ step, the current operating characteristics of the weight bearing machinery are approximated from the series of $1^{\text {st }}$ step; and in the $3^{\text {rd }}$ step, the parameters from the $2^{\text {nd }}$ step are utilized to determine the payload of the shovel.

Slob (2007)proposed a load sensing pin attached at the shovel sheave to estimate the payload of the electric mining shovel. The load pin measures the static, in-line torque directly. The reaction force on the clevis pin, supporting the sheave, is measured and transmitted through a Wheatstone bridge to the channels of the profibus.

Both the truck and the shovel-based payload measurement systems are dependent on equipment health and need calibration over time for accuracy. In the next section a payload calibration scheme is proposed utilizing ground-based scales.

\section{A Proposed Scheme for Payload Calibration}

The proposed scheme is shown in Figure 1. In this scheme, a ground-based scale is used to accurately measure the truck payloads. These measurements can further be used to adjust the payload measurement systems. As described in the Figure 1, the scheme consists of five measurements:

i. Empty Truck Weight: First, empty weight of the truck is measured after a thorough cleaning. Cleaning the truck is important as there could be considerable dirt attached to the underbody and some payload may be sticking with the truck bed. For this measurement, the empty trucks are brought to the scale and an empty truck weight is recorded.

ii. Shovel Payload Measurement: Second, the payload measurement is recorded at the shovel loading. Modern shovels have built-in payload measurement systems.

iii. On-Truck Scale Measurement: This is generally measured after the truck has covered some distance and is engaged in $2^{\text {nd }}$ gear. This measurement can be recorded at the scales as well as most of the scales continuously records the measurement and then lock a consistent value. 
iv. Scale Measurement: Fourth measurement is recorded at the scales on a pad that is specially prepared for this calibration purposes.

v. Dump Site Measurement: Finally, the payload is measure again at the dump site. Dump sites at the crushers have scales as well that calculate the total weight dumped on the screen of the crusher.

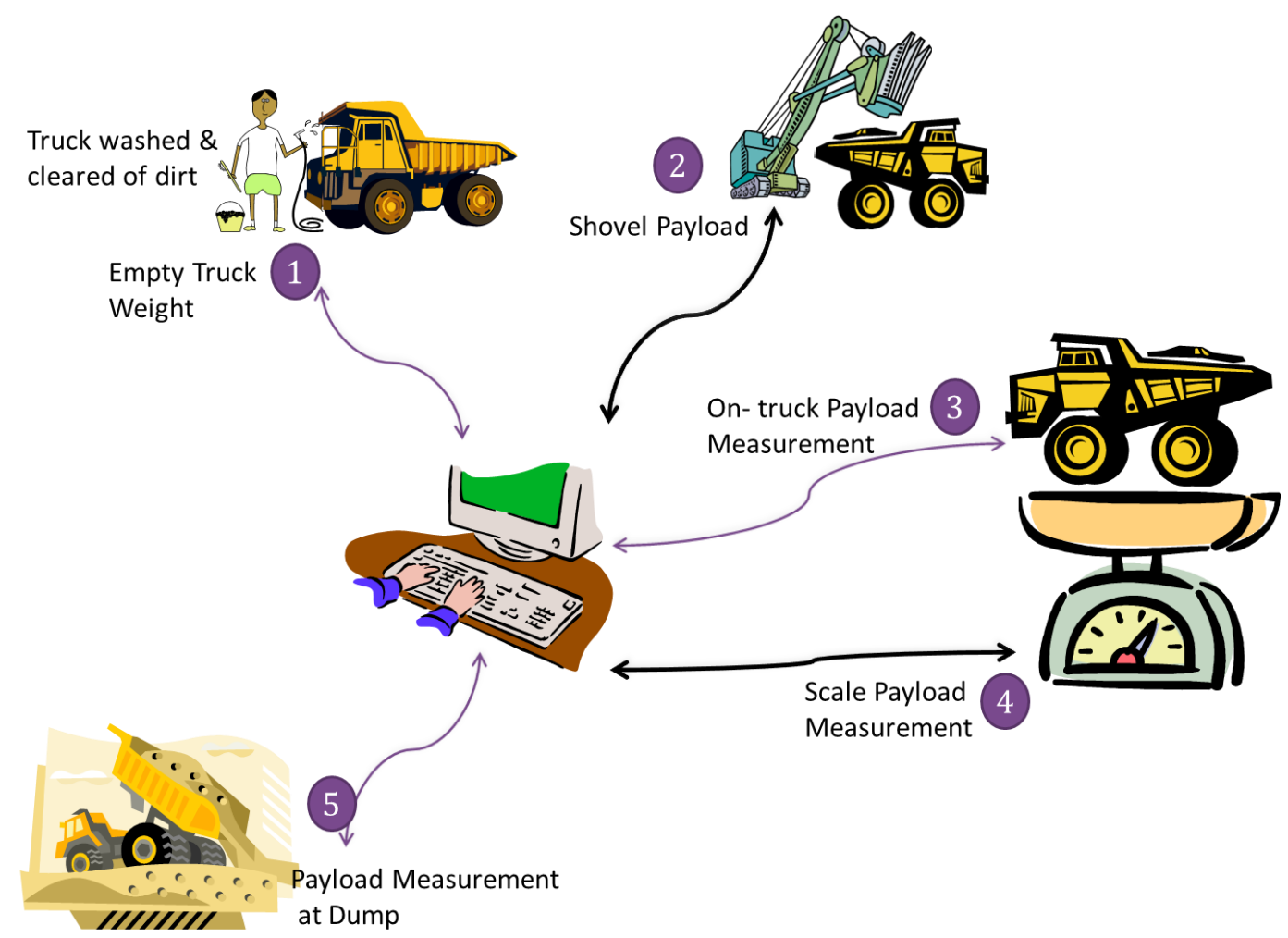

Figure1. Payload measurement and calibration scheme. Five measurements are recorded: (i) empty weight, (ii) payload measurement at the shovel, (iii) on-truck scale measurement, (iv) payload measurement at scales, (v) payload measurement at dump

\subsection{Selecting a Site for Scale Pad}

As most of the modern trucks weigh the payload when they start their haul and are on a flat ground, therefore, the scale pad should be selected close to the loading location when the truck is sure to be engaged in 2nd gear. Or if the conditions don't permit, then the payload information of on-board truck scale should be taken when the haul trucks measure the truck payload. The caution must be exercised as the on-truck scale might be giving a wrong estimate of the truck load when parked on the scale. It is important that the pad is prepared on a firm ground to minimizes the settlement. Old and well compacted haul roads are a good consideration for the pad site.

\subsection{Scales}

The big flat-bed scales should be utilized for this operation. Two stand-alone scales should be utilized for the calibration process. The ground underneath the scales must be compacted to avoid any settlement of the scales during calibration process. Two separated scales are better to avoid scale system inaccuracies. These scales should be separated enough to ensure that the tires park at the center of each scale. The scales must be calibrated independently and periodically against an external calibrated load cell or a known weight. For this purpose, a few concrete blocks of known weight can be utilized to test the accuracy of the scales.

The two scales must be leveled, and a level should be run every now and then to ensure the scales are level and are at the same elevation. The ramp for the pad should be compacted hard as well. To avoid settlement during the measurement, a proper mixture of rock, sand, and dirt should be utilized to minimize the settlement. The pad should be long and wide enough keeping in mind the safety and truck dimensions. 


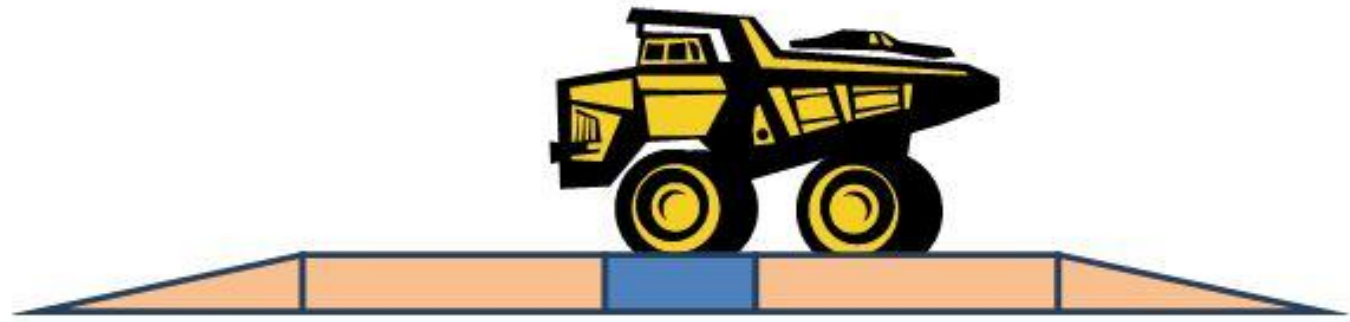

Figure2. A schematic representation of payload calibration pad

\subsection{Measurements}

The trucks should be free from excessive dirt and mud and any material inside the truck tray or underneath the truck body. They should be washed and if necessary, use a backhoe to clean the truck tray. The fuel tanks should be filled to avoid any later changes in the fuel levels. The trucks should enter the pad at a slow and safe speed. And a guide should ensure the wheels are parked at the center of the scale. The scale readings should be noted when the truck is fully stopped and free from vibrations. After the scale readings for the front wheels the truck should advance slowly to bring the rear tires centered on the scale. The measurements should be taken only after the truck has come to a complete stop again. The truck then should enter from the opposite direction on the scales and the whole above procedure should be repeated. This would give the empty weight of the truck. If these two readings vary by more than acceptable tolerance limit, the process should be repeated and if the error persists, the scale calibration should be tested again. The tolerance limit is a relative term and depends upon the sensitivity of the scales and accuracy of the on-truck scales. The empty weight of the truck should also be checked against the manufacturer supplied weight of the empty gross vehicle weight (GVW) adjusted for the fuel level. The modern fuel tanks carry more than 30 tons of fuel and this can considerably change the payload measurements.

The trucks should then start their normal business operation of material haulage i.e. take the load from shovel and move towards dump. This time the trucks again should stop at scale pad for weight measurements. The same measurement procedure should be repeated as was done for the empty truck weight measurement. However, this time few more readings are required. The material distribution should be good, if the load is off-centered those truck loads should be eliminated from the measurements.

Every time the truck must report the following:

i. Load shown by the shovel payload measurement system

ii. Load at the loading point, when the truck was parked under the shovel

iii. Load when the truck engaged into the $2^{\text {nd }}$ gear, or the manufacturer description of payload measurement point

iv. Fuel level, for weight adjustments

A minimum of five different loaded truck measurements should be made for the calibration process to safeguard against human and systematic errors.

\subsection{Calibration}

The accurate truck payload can be calculated by subtracting the empty truck weight from the loaded truck weights. The difference between the on-board truck payload and the scale measurement should be recorded for all the readings. If the absolute difference is outside the tolerance limits, defined by the accuracy of the scales and the on-board truck payload systems, the truck scales must be calibrated. Some truck payload systems can be tweaked on-site to adjust the payload readings. More payload reading would be required if the systems is being calibrated on site. If the system fails to give a consistent payload reading, the whole system should be reported to the manufacturer for repair and adjustments. Further, if the measurements show a crisscross loading pattern, where one pair of struts continuously shows more load than the other, those struts should be reported for repairs and adjustments. 


\section{VOLUMETRIC CAPACITY OF TRUCKS AND DENSITY MEASUREMENTS}

While the payload measurement is the primary objective of the haul trucks, however, some other important information can also be gathered during this process e.g. volumetric capacity of haul trucks, density of materials for different areas of the mine. A method for calculating the volumetric capacity of the haul trucks is described in US patent No. 7917266(Hagenbuch, 2011), issued on march 29, 2011, and can be used for this purpose. The method can be extended to measure the density of the material as well, where the truck trays are scanned, both empty and with material. The empty and loaded beds of the trucks should be scanned by modern surveying equipment to take enough points to make a 3-D representation of the truck tray in a graphics or mine design software to calculate the volume of the material carried by the truck. This volume information and the mass information from the scales can be used to calculate the density of the material accurately.

\section{A CaSe STUdy}

A payload calibration study was conducted at a large surface mining operation using this methodology. The study was aimed to verify the accuracy of the on-truck payload systems, and to calculate the volume and density of material being carried by haul trucks.

Overall, 31 haul trucks total were analyzed in this study. Of those trucks, 17 trucks (54\%) did not have issues with their payload systems, 4 trucks $(13 \%)$ had questionable payload systems, and 10 trucks $(32 \%)$ were confirmed as having payload system issues as the error was consistently more than the desired tolerance limit of 5\%. The 14 trucks with questionable or confirmed payload system issues were reported to maintenance.

In addition to verifying the accuracy of haul truck payload systems, scans were performed to calculate the volume and density of material in locations of the mine. Samples were taken from two locations. The study found a difference of $14 \%$ difference in the bulk density at two locations.

\section{CONCLUSION}

Accurate payload measurement for the haul trucks is very important and crucial for efficient and safe mining operations. The overloaded trucks are a safety hazard and impact negatively on the truck component life and haul road. The modern on-truck payload measurement systems only measure accurately when the truck start the haul. The shovel loading is important to avoid overloads and under loads; however, the system needs more work towards its accuracy. The truck on-truck payload measurement systems must be calibrated regularly using external scales. Besides the calibration purposes, these give important indication towards operator loading trends and truck suspension problems and can be used for accurate density calculations.

\section{REFERENCES}

[1] AFRICA, H. W. M. I. I.(2011). New system to curb road damage and truck overloading. Retrieved from http://www.howwemadeitinafrica.com/new-system-to-curb-road-damage-and-truck-overloading/10806/

[2] Bender, J. L.(2005).US Patent No. 6858809.

[3] Caterpillar. (2008).Caterpillar Quarry and Construction Truck 10/10/20 Payload Management Guidlines. In (Vol. TEKQ0616).

[4] Caterpillar. (2009).Caterpillar Performance Handbook (39 ed.). Peoria, IL: Caterpillar Inc, .

[5] Filas, F. J.(2002).Excavation, Loading, and Material Transport. In R. L. Lowrie (Ed.), SME Mining Reference Handbook. Littleton, CO: Society for Mining, Metallurgy, and Exploration.

[6] Foley, D. E., Gipp, G. H., Schwader, W. G., Sells, C. L., Smittkamp, J. A., \& Stahl, A. L. (1987).US Patent No. 4635739.

[7] Great-Mining.(2011).Lease of overloaded mining trucks are going to be cancelled. Retrieved from http://www.greatmining.com/mining-industry-issues/?p=6

[8] Hagenbuch, L. G.(2011).US Patent No. 7917266.

[9] Hays, M. R.(1990).Trucks.In B. A. Kennedy (Ed.), Surface Mining Handbook. Littleton, CO: Society for Mining, Metallurgy, and Exploration.

[10] Kecojevic,V.,\& Komljenovic. (2010). Haul Truck Fuel Consumption and CO2 Emissions Under Various Engine Load Conditions. SME Mining Engineering, 62(12), 47-52.

[11] Kevin, L. J., Ronald, S. K., \& Joes, P. L. (2003). US Patent No. 6601013 B2 
[12] Kyrtsos, C. T., \& Gudat, A. J. (1993). US Patent No. 5182712

[13] Mcaree, P. R., \& Wauge, D. H. (2012).

[14]miningsafety.co.za. Mining Vehicle $\quad$ Overloading. Retrieved from http://www.miningsafety.co.za/pages.aspx $? \mathrm{i}=25$

[15]Runge, I. (1998). Mining Economics and Strategy. Paper presented at the Society for Mining, Metallurg, and Exploration, Littleton, CO.

[16] Slob, J. J. (2007). Payload Estimation for Electric Mining Shovels using a Load Sensing Pin. (Traineeship report Traineeship Report), University of Queensland, Brisban. Retrieved from http://www.mate.tue.nl/mate/ pdfs/7948.pdf (057)

[17] Soofastaei, A., Aminossadati, S., Kizil, M., Knights, P. J. I. J. o. M. S., \& Technology. (2016). A comprehensive investigation of loading variance influence on fuel consumption and gas emissions in mine haulage operation. 26(6), 995-1001.

[18] Sorrells, G. K. (1989). USA Patent No. 4835719.

Citation: Muhammad Raza (2020)" Calibration of Payload Measurement System for Mining Haul Trucks, International Journal of Mining Science (IJMS), 6(2), pp.34-40, DOI: http://dx.doi.org/10.20431/24549460.0602003

Copyright: () 2020 Muhammad Raza. This is an open-access article distributed under the terms of the Creative Commons Attribution License, which permits unrestricted use, distribution, and reproduction in any medium, provided the original author and source are credited 